\title{
Rancang Bangun Sistem Deteksi Lingkungan Kerja Industri Berbasis GSM
}

\author{
Bahtiar Adip Rifa'i' ${ }^{1}$, Waluyo², Rachmad Saptono ${ }^{3)}$ \\ 1,2,3 Program Studi Jaringan Telekomunikasi Digital, \\ Jurusan Teknik Elektro, Politeknik Negeri Malang, Indonesia \\ $\underline{{ }^{1} \text { bachtiarbakrie02@gmail.com, }}{ }^{2}$ waluyo@polinema.ac.id, ${ }^{3}$ rachmad.saptono@polinema.ac.id
}

\begin{abstract}
Industrial accidents are accidents that occur in the workplace, especially in an industrial environment. The most important factors in the occurrence of work accidents are technical equipment, work environment, and the workers themselves. Lighting that is not enough to illuminate workers when using machines can cause work accidents during the production process. In addition, hot conditions can also cause work accidents because hot temperatures make the body uncomfortable at work, reduce agility, interfere with the carefulness of the brain, and ease emotions so that workers cannot concentrate and can cause work accidents. The purpose of this research is to create a system that can detect temperature, smoke, and light in a GSM-based industrial environment. This system can help prevent industrial accidents by obtaining information about industrial environmental conditions for workers in the form of SMS Temperature, smoke, and light sensors will send SMS information when each sensor exceeds the threshold value specified in the program. Information delivery is carried out using 3 different providers, namely Three, Indosat, and Telkomsel by comparing the amount of delay. The test results can be concluded that the three sensors can work well. The temperature sensor can detect temperature with an average error value of $0.03 \%$. The smoke sensor can detect smoke with an average value of $0 \%$. Provider Three can send information with a small average delay, namely 1.46s. Indosat providers can send information with an average delay of 3.68s. Telkomsel providers can send information with an average delay of $1.52 \mathrm{~s}$.
\end{abstract}

Keywords - Arduino Uno, GSM sim900, Delay, Industrial environment, Detection

Abstrak - Kecelakaan industri adalah kejadian kecelakaan yang terjadi di tempat kerja khususnya di lingkungan industri. Faktor yang paling utama timbulnya kecelakaan kerja adalah faktor peralatan teknis, lingkungan kerja, dan pekerja itu sendiri. Pencahayaan yang kurang dalam menerangi pekerja saat memakai mesin bisa menyebabkan kecelakaan kerja saat proses produksi berjalan. Selain itu kondisi yang panas juga bisa menyebabkan kecelakaan kerja karena suhu yang panas membuat tubuh tidak nyaman dalam bekerja, mengurangi kelincahan, mengganggu kecermatan otak, serta memudahkan emosi sehingga pekerja tidak dapat berkonsentrasi dan dapat menyebabkan kecelakaan kerja. Tujuan dari penelitian ini adalah membuat sistem yang dapat mendeteksi suhu, asap, dan cahaya pada lingkungan industri berbasis GSM. Sistem ini dapat membantu mencegah terjadinya kecelakaan industri dengan cara mendapatkan informasi mengenai kondisi lingkungan industri bagi para pekerja berupa SMS. Sensor suhu, asap, dan cahaya akan mengirimkan informasi berupa SMS apabila masing-masing sensor melebihi nilai batas ambang yang telah ditentukan dalam program. Pengiriman informasi dilakukan menggunakan 3 provider berbeda, yaitu Three, Indosat, dan Telkomsel dengan membandingkan besarnya delay. Hasil pengujian dapat disimpulkan bahwa ketiga sensor dapat bekerja dengan baik. Sensor suhu dapat mendeteksi suhu dengan nilai rata-rata error $0,03 \%$. Sensor asap dapat mendeteksi asap dengan nilai rata-rata $0 \%$. Provider Three dapat mengirimkan informasi dengan rata-rata delay yang kecil, yaitu 1,46s. Provider Indosat dapat mengirimkan informasi dengan ratarata delay sebesar 3,68s. Provider Telkomsel dapat mengirimkan informasi dengan rata-rata delay sebesar 1,52s.

Kata kunci- Arduino Uno, GSM sim900, Delay, Lingkungan Kerja, Deteksi

\section{PENDAHULUAN}

Indonesia merupakan negara berkembang yang dalam usahanya untuk mencapai pertumbuhan ekonomi salah satunya mengandalkan pada sektor industri. Semakin tinggi teknologi yang digunakan, semakin tinggi pula risiko kecelakaan industri yang dihadapi. Kecelakaan industri adalah kejadian kecelakaan yang terjadi di tempat kerja khususnya di lingkungan industri . Faktor yang paling utama timbulnya kecelakaan kerja adalah faktor peralatan teknis, lingkungan kerja, dan pekerja itu sendiri. Peralatan teknis yang kurang aman, atau mesin-mesin yang tidak dirancang baik untuk dilengkapi dengan alat pengamanan secukupnya. Lingkungan kerja yang tidak mendukung dapat menurunkan tingkat konsentrasi pekerja terhadap tugas-tugas yang ditanganinya. Demikian pula para pekerja itu sendiri dapat menjadi faktor penyebab bila mereka tidak mendapat latihan yang memadai ataumereka belum berpengalaman dalam tugasnya [1][2]. Menurut Barathi, menyatakan pencahayaan yang kurang dalam menerangi pekerja saat memakai mesin bisa menyebabkan kecelakaan kerja saat proses produksi berjalan. Selain itu kondisi yang panas juga bisa menyebabkan kejadian kecelakaan kerja karena suhu yang panas membuat tubuh tidak nyaman dalam bekerja, mengurangi kelincahan, mengganggu kecermatan otak, serta memudahkan emosi sehingga pekerja tidak dapat berkonsentrasi dan dapat menyebabkan kecelakaan kerja[3].

Nilai Ambang Batas (NAB) adalah standar faktor tempat kerja yang dapat diterima tenaga kerja tanpa mengakibatkan penyakit atau gangguan kesehatan, dalam pekerjaan sehari-hari untuk waktu tidak melebihi 8 jam sehari atau 40 jam seminggu[4]. Nilai ambang batas untuk suhu berdasarkan 
Keputusan Menteri Tenaga Kerja nomor : kep- sl/men/1999 tanggal : 16 April 1999. Menurut (Wignjosoebroto, 2008) Suhu yang baik di tempat kerja yang memberikan produktivitas kerja yang tinggi adalah pada $24^{\circ} \mathrm{C}-27^{\circ} \mathrm{C}$ [4]-[6]. Pengaruh tingkat suhu pada tubuh manusia saat bekerja berbeda-beda seperti berikut:

- $\quad+49^{\circ} \mathrm{C}$ : suhu dapat ditahan sekitar 1 jam, tetapi jauh diatas tingkat kemampuan fisik dan mental

- $+30^{\circ} \mathrm{C}$ : Aktivitas mental dan daya tanggap mulai menurun dan cenderung untuk membuat kesalahan dalam pekerjaan, timbul kelelahan fisik.

- $\quad+24^{\circ} \mathrm{C}$ : Kondisi optimum.

- $\quad+10^{\circ} \mathrm{C}$ : Kelakuan fisik yang extreme mulai muncul

Nilai ambang batas untuk karbon monoksida berdasarkan Peraturan Menteri Tenaga Kerja dan Transmigrasi tentang Nilai Ambang Batas Faktor Fisika dan Faktor Kimia di Tempat Kerja (PER.13/MEN/X/2011) adalah 25 ppm.

\section{METODE}

\section{A. Rancangan Penelitian}

Rancangan penelitian dilakukan untuk memperinci dalam pembuatan perangkat agar hasil dapat didapatkan secara runtun. Rancangan penelitian yang akan dilakukan dalam pembuatan sistem ditunjukkan pada gambar dibawah ini.

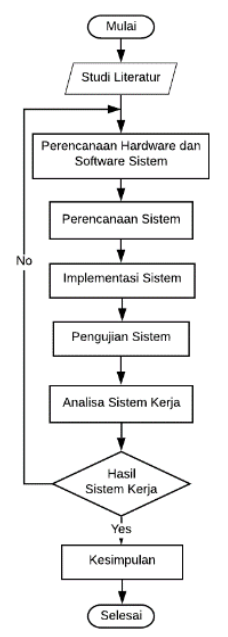

Gambar 1. Rancangan penelitian

Pada gambar 1 di atas diperlihatkan rancangan penelitian yang dilakukan saat penelitian. Studi literatur mengenai sensor suhu, sensor asap, sensor cahaya komunikasi data pada sistem, dan lainnya. Pada tahap ini, ditentukan spesifikasi alat dan bahan, pemrograman yang digunakan, dan sistem komunikasi yang digunakan. Perencanaan sistem membahas tentang perencanaan dan pembuatan desain perangkat dari sistem. Diantaranya, desain secara mekanik dan elektrik serta perkiraan letak perangkat yang digunakan. Dalam penelitian ini, akan dibuat alat Sistem monitoring lingkungan indsutri menuju ke pengguna berupa SMS. Pembuatan alat sistem beserta program yang diinput ke arduino uno. Sistem yang telah dirancang dan dibuat sebelumnya, akan dilakukan uji coba.
Hasil dari pengujian sistem sesuai dengan harapan atau tidak. Analisa sistem yang telah diuji diantaranya alat dan program dapat berjalan dengan sesuai, antar perangkat dapat berkomunikasi, antar perangkat dapat saling mengirimkan data untuk komunikasi perangkat. Tahap ini merupakan pembuatan kesimpulan yang diambil berdasarkan rumusan masalah, pembutanan sistem serta hasil pengujian dan analisa yang dilakukan.

\section{B. Perencanaan Sistem}

Diagram blok dari sistem "Rancang Bangun Sistem Deteksi Lingkungan Kerja Industri Berbasis GSM" disajikan dalam gambar seperti dibawah ini:

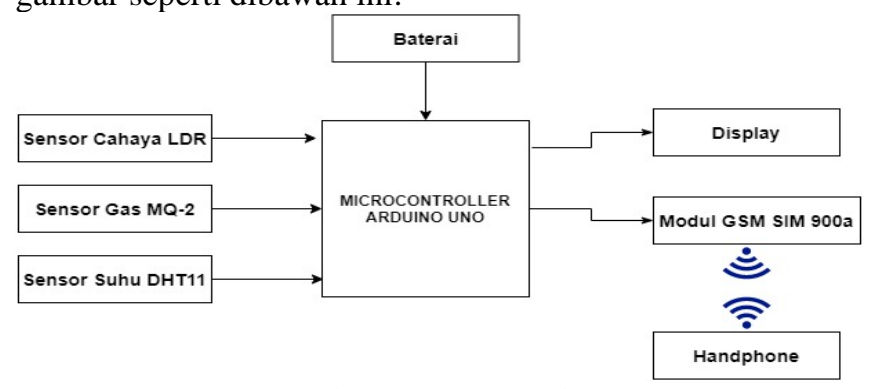

Gambar 2. Perencanaan sistem

Dari Gambar 2 dijelaskan blok diagram perancangan sistem pada penelitian "Rancang Bangun Sistem Deteksi Lingkungan Kerja Industri Berbasis GSM". Dari ketiga sensor atau indikator akan memberikan input ke mikrokontroller arduino uno yang telah terhubung. Kemudian mikrokontroller secara instant memproses data yang diterima. Saat mendapat sinyal peringatan dari salah satu sensor mikrokontroller otomatis mengkomunikasikan data yang diterima ke modul GSM yang sudah terhubung dengannya lalu mengirimkan pesan berupa SMS kepada pengguna yang dituju sebagai peringatan.

\section{Perencanaan Alat}

Seluruh komponen akan dirangkai seperti gambar dibawah ini yang terdiri dari arduino uno, sensor shield, sensor asap MQ-2, LCD (Liquid Crystal Display), Modul SIM900a dan baterai kemudian di implementasikan ke dalam gambar selanjutnya.

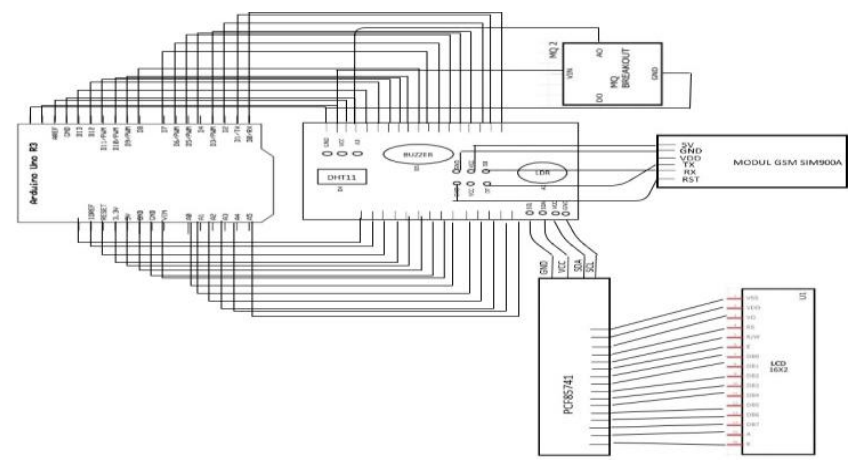

Gambar 3. Perencanaan alat

Pada Gambar 3 merupakan desain perancangan sistem dimulai dari baterai sebagai catu daya yang terhubung pada 
jack power arduino uno. Kemudian sensor shield arduino yang ditumpangkan pada arduino uno. Pada sensor shield arduino uno terdapat beberapa komponen akan tetapi pada sensor shield tersebut hanya menggunakan sebagian dari banyaknya komponen yang tersedia. Sensor suhu DHT11 terhubung pada pin D4, sensor asap MQ-2 terhubung pada pin A3, sensor cahaya LDR (Light Dependent Resistor) terhubung pada pin A1, modul GSM sim900a terhubung pada pin D7 dan D8, Buzzer terhubung pada pin D5, LED (Light Emitting Diode) merah pada pin D12, LED (Light Emitting Diode) biru pada pin D13. Keseluruhan komponen tersebut terhubung pada pin arduino uno yang tersedia.

\section{HASIL DAN PEMBAHASAN \\ A. Pengujian Kalibrasi Sensor Suhu DHT 11}

Pengujian kalibrasi dilakukan untuk mengatur dan mengecek keakurasian dari suatu alat ukur yaitu dengan cara dengan membandingkan dengan standart atau tolak ukur. Kalibrasi diperlukan untuk memastikan bahwa hasil pengukuran didapat akurat dan sesuai dengan alat ukur sebenarnya. Alat yang digunakan sebagai acuan untuk kalibrasi disini alat thermometer. Pengujian dilakukan dengan membandingkan nilai yang dihasilkan dari pembacaan thermometer dan sensor suhu DHT 11 yang dapat dibaca melalui LCD (Liquid Crystal Display). Kemudian thermometer dan sensor suhu DHT 11 ditempatkan pada kondisi suhu yang sama lalu dilakukan pencatatan dari hasil yang terbaca dari kedua alat tersebut. Setelah itu dilakukan perhitungan hasil dari thermometer dan sensor suhu DHT11 untuk mendapatkan presentase error yang didapatkan.

TABEL I.

Pengujian Kalibrasi Sensor SuHu DHT 11

\begin{tabular}{cccc}
\hline Percobaan & $\begin{array}{c}\text { Pembacaan } \\
\text { Sensor }\left({ }^{\circ} \mathbf{C}\right)\end{array}$ & $\begin{array}{c}\text { Pembacaan Alat } \\
\text { Ukur }\left({ }^{\circ} \mathbf{C}\right)\end{array}$ & $\begin{array}{c}\text { Error } \\
(\%)\end{array}$ \\
\hline 1 & 29 & 30,1 & 0,04 \\
2 & 30 & 31,2 & 0,04 \\
3 & 30 & 29,7 & 0,01 \\
4 & 31 & 31,8 & 0,03 \\
5 & 31 & 31,6 & 0,02 \\
6 & 31 & 31,6 & 0,02 \\
7 & 32 & 33,1 & 0,03 \\
8 & 31 & 32,7 & 0,05 \\
9 & 31 & 31,4 & 0,01 \\
10 & 30 & 31,1 & 0,04 \\
\hline \multicolumn{4}{c}{} \\
\hline
\end{tabular}

Pada Tabel I di atas menunjukkan bahwa perbandingan antara sensor suhu DHT 11 dengan alat ukur thermometer sebagai pembanding hasilnya tidak jauh berbeda. Dari hasil sensor suhu DHT 11 dan alat ukur thermometer menunjukkan presentase error dengan rata-rata $0,03 \%$.

\section{B. Pengujian Kalibrasi Sensor Asap $M Q-2$}

Pengujian dilakukan dengan membandingkan pembacaan sensor asap yang ditampilkan pada LCD (Liquid Crystal Display) dengan serial monitor pada aplikasi arduino IDE.
TABEL II.

PenguJian KALIBRASi SENSOR ASAP MQ-2

\begin{tabular}{cccc}
\hline Percobaan & $\begin{array}{c}\text { Pembacaan } \\
\text { Sensor (ppm) }\end{array}$ & $\begin{array}{c}\text { Serial Monitor } \\
\text { Arduino }(\mathbf{p p m})\end{array}$ & $\begin{array}{c}\text { Error } \\
\mathbf{( \% )}\end{array}$ \\
\hline 1 & 0,05 & 0,05 & 0 \\
2 & 0,08 & 0,08 & 0 \\
3 & 0,05 & 0,05 & 0 \\
4 & 0,06 & 0,06 & 0 \\
5 & 0,05 & 0,05 & 0 \\
6 & 0,05 & 0,05 & 0 \\
7 & 0,06 & 0,06 & 0 \\
8 & 0,05 & 0,05 & 0 \\
9 & 0,08 & 0,08 & 0 \\
10 & 0,05 & 0,05 & 0 \\
\hline \multicolumn{4}{c}{} \\
\hline
\end{tabular}

Pada tabel 3.2 menunjukkan hasil perbandingan dari pembacaan sensor asap MQ-2 yang ditampilkan pada LCD (Liquid Crystal Display) dan serial monitor hasilnya tidak ada perbedaan. Dari hasil perhitungan menunjukkan presentase error dengan rata-rata $0 \%$

\section{Pengujian Kalibrasi Sensor Suhu DHT 11}

Penelitian ini digunakan sensor cahaya yang menggunakan komponen elektronika yaitu LDR (Light Dependent Resistor). Fungsi LDR (Light Dependent Resitor) pada penelitian ini yaitu hanya sebagai detektor kondisi gelap atau intensitas cahaya yang redup pada suatu lingkungan. Prinsip kerja LDR adalah semakin banyak cahaya yang diterima olehnya maka nilai resistansinya akan menurun dan sebaliknya apabila semakin sedikit cahaya yang diterima maka akan semakin besar nilai resistansinya. Dari prinsip kerja LDR (Light Dependent Resistor) tersebut yang sudah umum untuk diketahui maka dalam penelitian ini tidak diperlukan kalibrasi

\section{Hasil Pembuatan Hardware}

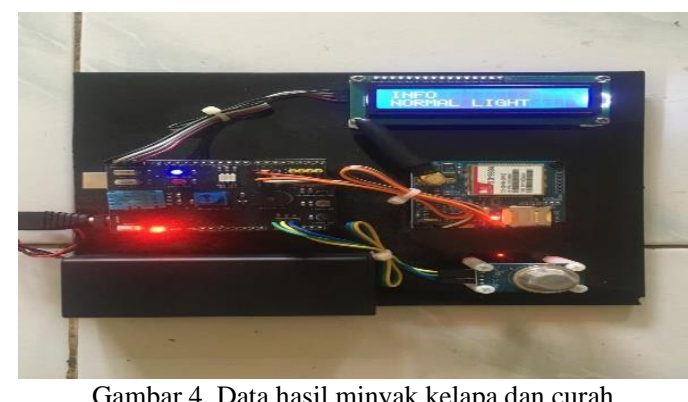

\section{E. Hasil Informasi SMS}

Pada gambar 5 di bawah menunjukkan informasi berupa SMS (Short Message Service) yang diperoleh pada saat awal sistem dinyalakan. Informasi pertama adalah intensitas cahaya menunjukkan kondisi normal. Informasi kedua merupakan kondisi sensor suhu DHT11 sebagai suhu pada awal saat sistem mulai dinyalakan menunjukan suhu dan kelembapan. Informasi terakhir merupakan kondisi sensor asap MQ-2 sebagai sensor asap yang menunjukkan kondisi normal dengan menunjukkan Jika sudah mendapat ketiga informasi tersebut 
dari masing-masing sensor artinya sistem sudah berjalan dengan baik dan sudah dapat digunakan.

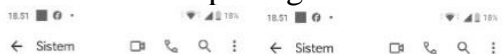

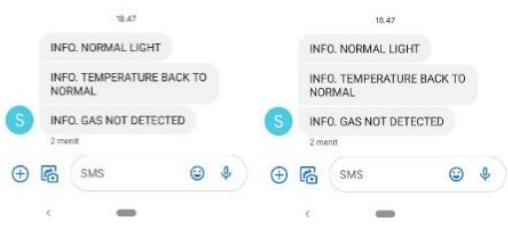

Gambar 5. Hasil informasi SMS

F. Hasil Pengujian Sensor Asap MQ-2

TABEL III.

PENGUJIAN MENGGUNAKAN SENSOR ASAP MQ-2

\begin{tabular}{ccc} 
Perocbaan & Kondisi & $\begin{array}{c}\text { Nilai Pembacaan } \\
\text { Sensor Asap (ppm) }\end{array}$ \\
\hline 1 & Belum ada karbon & 0,49 \\
2 & monoksida & 0,52 \\
3 & & 0,45 \\
5 & & 0,47 \\
\hline 6 & Terdapat karbon & 0,68 \\
\hline 7 & monoksida diarea sensor & 11.02 \\
8 & & 19,96 \\
9 & & 12,09 \\
10 & & 19,25 \\
\hline 11 & & 15,27 \\
12 & & 28,23 \\
13 & Terdapat karbon & 38,09 \\
\hline 15 & kepeksidan yang tebal & 37,07 \\
\hline & & 45,87 \\
\hline & & 61,72 \\
\hline
\end{tabular}

Dari tabel III dilakukan percobaan pada sensor asap MQ-2 sebanyak 15 kali. Pada percobaan 11 hingga 15 dapat disimpulkan bahwa sistem secara otomatis mengirimkan informasi berupa SMS menuju pengguna dikarenakan sensor asap MQ-2 mendeteksi melebihi nilai ambang batas yang telah ditentukan. Nilai ambang batas sistem adalah 25 ppm sesuai peraturan menteri tenaga kerja dan transmigrasi.

\section{G. Hasil Pengujian Sensor Suhu 11}

TABEL IV.

HASIL PENGUJIAN SENSOR SUHU 11

\begin{tabular}{ccc}
\hline Percobaan & $\begin{array}{c}\text { Nilai pembacaan sensor } \\
\text { suhu DHT11 }\left({ }^{\circ} \mathbf{C}\right)\end{array}$ & Status \\
\hline 1 & 26 & Aman \\
2 & 27 & Aman \\
3 & 27 & Aman \\
4 & 28 & Aman \\
5 & 29 & Aman \\
6 & 30 & Normal \\
7 & 31 & Normal \\
8 & 33 & Normal \\
9 & 37 & Normal \\
10 & 38 & Normal \\
11 & 42 & Overheat \\
12 & 43 & Overheat \\
13 & 40 & Overheat \\
14 & 46 & Overheat \\
15 & 48 & Overheat \\
\hline
\end{tabular}

Dari tabel IV merupakan hasil pengujian sensor suhu DHT 11 dengan melakukan percobaan sebanyak 15 kali. Pada sistem telah ditentukan bahwa sistem akan mengirimkan informasi berupa SMS saat sensor suhu mendeteksi diatas $40^{\circ} \mathrm{C}$. Pada tabel 4.3 percobaan 1 sampai dengan 10 sensor mendeteksi suhu $26-38^{\circ} \mathrm{C}$ sehingga sistem tidak mengirimkan informasi tetapi hanya dapat dilihat melalui layar LCD. Sedangkan pada percobaan 11 sampai 15 sensor mendeteksi suhu $40-48^{\circ} \mathrm{C}$ sehingga sistem mengirimkan informasi berupa SMS kepada pengguna.

\section{H. Hasil Pengujian Sensor Cahaya LDR}

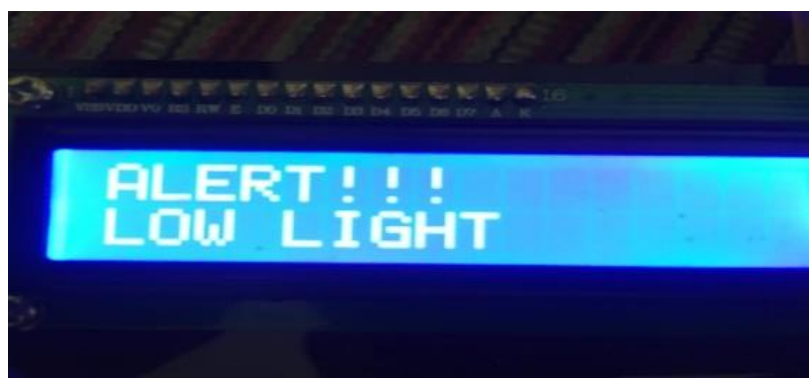

Gambar 6. Hasil pengujian sensor cahaya LDR

Dari hasil perngujian sensor LDR (Light Dependent Resistor) pada gambar 4.3 menunjukkan kondisi lingkungan sedang butuh penerangan karena intensitas cahaya yang kurang. Sensor cahaya hanya memastikan kondisi intensitas cahaya pada lingkungan. Pengujian sensor cahaya dilakukan dengan menutupi sensor cahaya dengan benda atau dapat diletakkan pada ruangan yang gelap

\section{Hasil Pengujian Delay Pengiriman Informasi SMS Provider Three}


TABEL V.

DELAY PROVIDER THREE

\begin{tabular}{|c|c|c|c|c|}
\hline $\begin{array}{c}\text { Percoba } \\
\text { an }\end{array}$ & Provider & $\begin{array}{c}\text { Waktu } \\
\text { Dikirim }\end{array}$ & $\begin{array}{c}\text { Waktu } \\
\text { Diterima }\end{array}$ & $\begin{array}{c}\text { Delay } \\
\text { (s) }\end{array}$ \\
\hline 1 & Three & $08: 24: 36: 43$ & 08:24:37:93 & 1,50 \\
\hline 2 & Three & 08:26:09:18 & 08:26:16:86 & 7,68 \\
\hline 3 & Three & 08:29:27:12 & 08:29:28:25 & 1,13 \\
\hline 4 & Three & 08:32:03:87 & 08:32:06:35 & 2,48 \\
\hline 5 & Three & 08:35:01:67 & 08:35:03:24 & 1,57 \\
\hline 6 & Three & $12: 03: 04: 73$ & 12:03:05:95 & 1,22 \\
\hline 7 & Three & $12: 05: 45: 90$ & $12: 05: 46: 70$ & 0,80 \\
\hline 8 & Three & $12: 09: 34: 81$ & 12:09:35:88 & 1,07 \\
\hline 9 & Three & $12: 11: 14: 47$ & $12: 11: 15: 26$ & 0,79 \\
\hline 10 & Three & $12: 16: 53: 02$ & $12: 16: 54: 35$ & 1,33 \\
\hline 11 & Three & $15: 45: 12: 49$ & $15: 46: 13: 63$ & 1,14 \\
\hline 12 & Three & $15: 46: 28: 34$ & $15: 46: 29: 10$ & 0,76 \\
\hline 13 & Three & $15: 48: 11: 07$ & 15:48:11:91 & 0,84 \\
\hline 14 & Three & $15: 49: 38: 02$ & $15: 49: 38: 58$ & 0,56 \\
\hline 15 & Three & $15: 53: 27: 68$ & $15: 53: 28: 71$ & 1,03 \\
\hline 16 & Three & 19:06:56:78 & 19:06:57:85 & 1,07 \\
\hline 17 & Three & $19: 08: 27: 69$ & 19:08:28:26 & 0,57 \\
\hline 18 & Three & 19:13:09:94 & $19: 13: 12: 14$ & 1,20 \\
\hline 19 & Three & $19: 15: 57: 39$ & $19: 15: 57: 05$ & 0,66 \\
\hline 20 & Three & 19:19:03:67 & 19:19:05:51 & 1,84 \\
\hline \multicolumn{4}{|c|}{ Rata-rata } & 1,46 \\
\hline
\end{tabular}

J. Hasil Pengujian Delay Pengiriman Informasi SMS Provider Indosat

TABEL VI.

DELAY PROVIDER INDOSAT

\begin{tabular}{ccccc}
\hline $\begin{array}{c}\text { Percoba } \\
\text { an }\end{array}$ & Provider & $\begin{array}{c}\text { Waktu } \\
\text { Dikirim }\end{array}$ & $\begin{array}{c}\text { Waktu } \\
\text { Diterima }\end{array}$ & $\begin{array}{c}\text { Delay } \\
\text { (s) }\end{array}$ \\
\hline 1 & Indosat & $07: 37: 23: 90$ & $07: 37: 28: 38$ & 4,48 \\
2 & Indosat & $07: 39: 34: 23$ & $07: 39: 37: 86$ & 3,63 \\
3 & Indosat & $07: 43: 12: 78$ & $07: 43: 16: 24$ & 3,46 \\
4 & Indosat & $07: 45: 56: 12$ & $07: 45: 59: 65$ & 3,53 \\
5 & Indosat & $07: 46: 47: 34$ & $07: 46: 51: 19$ & 3,85 \\
6 & Indosat & $12: 39: 13: 98$ & $12: 39: 17: 69$ & 3,71 \\
7 & Indosat & $12: 41: 09: 02$ & $12: 41: 12: 32$ & 3,30 \\
8 & Indosat & $12: 42: 47: 28$ & $12: 42: 50: 78$ & 3,50 \\
9 & Indosat & $12: 43: 53: 12$ & $12: 43: 56: 59$ & 3,47 \\
10 & Indosat & $12: 45: 41: 09$ & $12: 45: 45: 14$ & 4,05 \\
11 & Indosat & $16: 12: 38: 89$ & $16: 12: 42: 52$ & 3,63 \\
12 & Indosat & $16: 13: 23: 71$ & $16: 13: 26: 81$ & 3,10
\end{tabular}

\begin{tabular}{ccccc}
\hline $\begin{array}{c}\text { Percoba } \\
\text { an }\end{array}$ & Provider & $\begin{array}{c}\text { Waktu } \\
\text { Dikirim }\end{array}$ & $\begin{array}{c}\text { Waktu } \\
\text { Diterima }\end{array}$ & $\begin{array}{c}\text { Delay } \\
\text { (s) }\end{array}$ \\
\hline 13 & Indosat & $16: 17: 49: 94$ & $16: 17: 53: 69$ & 3,75 \\
14 & Indosat & $16: 18: 54: 09$ & $16: 18: 57: 49$ & 3,40 \\
15 & Indosat & $16: 20: 17: 56$ & $16: 20: 21: 14$ & 3,58 \\
16 & Indosat & $20: 34: 31: 67$ & $16: 34: 34: 97$ & 3,30 \\
17 & Indosat & $20: 36: 25: 09$ & $20: 36: 28: 35$ & 3,26 \\
18 & Indosat & $20: 37: 48: 54$ & $20: 37: 52: 94$ & 4,40 \\
19 & Indosat & $20: 39: 10: 62$ & $20: 39: 15: 13$ & 4,51 \\
20 & Indosat & $20: 40: 53: 92$ & $20: 40: 57: 68$ & 3,76 \\
\hline & & Rata-rata & 3,68 \\
\hline
\end{tabular}

K. Hasil Pengujian Delay Pengiriman Informasi SMS Provider Telkomsel

TABEL VII.

DELAY PROVIDER TELKOMSEL

\begin{tabular}{ccccc}
\hline $\begin{array}{c}\text { Percoba } \\
\text { an }\end{array}$ & Provider & $\begin{array}{c}\text { Waktu } \\
\text { Dikirim }\end{array}$ & $\begin{array}{c}\text { Waktu } \\
\text { Diterima }\end{array}$ & $\begin{array}{c}\text { Delay } \\
\text { (s) }\end{array}$ \\
\hline 1 & Telkomsel & $07: 10: 13: 59$ & $07: 10: 15: 51$ & 1,92 \\
2 & Telkomsel & $07: 11: 03: 94$ & $07: 11: 05: 40$ & 1,46 \\
3 & Telkomsel & $07: 15: 09: 17$ & $07: 15: 10: 58$ & 1,41 \\
4 & Telkomsel & $07: 16: 56: 52$ & $07: 16: 58: 23$ & 1,71 \\
5 & Telkomsel & $07: 18: 48: 78$ & $07: 18: 50: 51$ & 1,73 \\
6 & Telkomsel & $11: 04: 45: 09$ & $11: 04: 46: 25$ & 1,16 \\
7 & Telkomsel & $11: 05: 56: 67$ & $11: 05: 58: 12$ & 1,45 \\
8 & Telkomsel & $11: 07: 03: 78$ & $11: 07: 05: 30$ & 1,52 \\
9 & Telkomsel & $11: 08: 29: 92$ & $11: 08: 31: 47$ & 1,55 \\
10 & Telkomsel & $11: 09: 52: 34$ & $11: 09: 53: 70$ & 1,36 \\
11 & Telkomsel & $15: 34: 56: 17$ & $15: 34: 57: 92$ & 1,75 \\
12 & Telkomsel & $15: 36: 32: 60$ & $15: 36: 34: 23$ & 1,63 \\
13 & Telkomsel & $15: 37: 58: 02$ & $15: 37: 59: 64$ & 1,62 \\
14 & Telkomsel & $15: 39: 06: 94$ & $15: 39: 08: 69$ & 1,75 \\
15 & Telkomsel & $15: 40: 32: 63$ & $15: 40: 33: 66$ & 1,03 \\
16 & Telkomsel & $19: 04: 09: 57$ & $19: 04: 11: 24$ & 1,67 \\
17 & Telkomsel & $19: 05: 41: 90$ & $19: 05: 41: 67$ & 1,77 \\
18 & Telkomsel & $19: 09: 01: 78$ & $19: 09: 03: 48$ & 1,70 \\
19 & Telkomsel & $19: 13: 24: 22$ & $19: 13: 25: 40$ & 1,18 \\
20 & Telkomsel & $19: 15: 13: 46$ & $19: 15: 14: 49$ & 1,03 \\
\hline & & Rata-rata & & 1,52 \\
\hline & & & & \\
\hline & & & \\
\hline
\end{tabular}

Dari grafik Gambar 7 diketahui nilai perband rata-rata delay dari masing-masing provider yang telah digunakan pada percobaan pengiriman data SMS (short message service). Provider pertama (Provider Three) memiliki rata-rata delay sebesar 1.46 second. Provider kedua (Provider Indosat) memiliki rata-rata delay sebesar 3.68 second. Provider ketiga 
(Provider Telkomsel) memiliki rata-rata delay sebesar 1.52 second. Dari ketiga provider tersebut, Provider Three yang memiliki nilai rata-rat delay paling sedikit dari proses perhitungan keseluruhan percobaan.

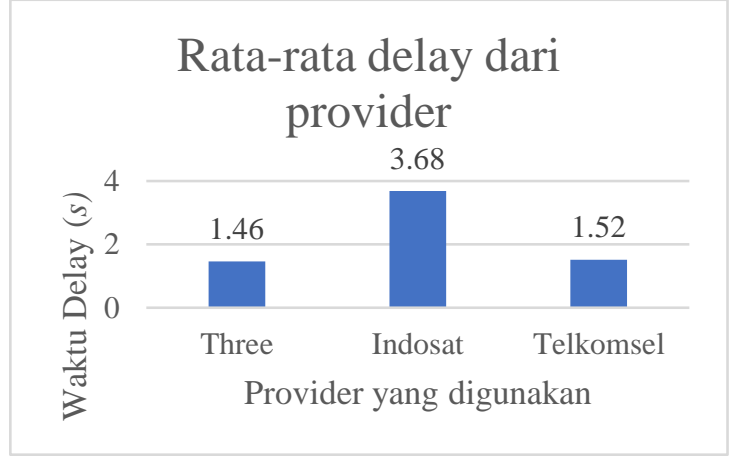

Gambar 7. Rata-rata delay

\section{KESIMPULAN}

Modul GSM sim900 mampu menjadi transmitter yang handal dalam pengiriman data SMS (Short Message Service). Seluruh sistem dari sensor, mikrokontroller hingga modul GSM sim900 mampu bekerja dengan baik dengan memberikan informasi inputan dari masing-masing sensor yang telah digunakan. Sensor suhu DHT11 mampu menjadi detektor suhu yang baik dengan menunjukkan presentase rata-rata error sebesar $0.03 \%$. Sensor Asap MQ-2 mampu menjadi detektor asap yang baik dengan menunjukkan presentase error sebesar $0 \%$.

\section{REFERENSI}

[1] Swaputri, Eka "Analisis Penyebab Kecelakaan Kerja (Studi Kasus di PT. Jamu Air Mancur)”, Skripsi Jurusan Ilmu Kesehatan Masyarakat, Fakultas Ilmu Keolahragaan, Universitas Negeri Semarang, 2009, hal.15.

[2] Darise, Idham Yusuf., "Sistem Monitoring Kualitas Lingkungan (Asap, Suhu, dan Intensitas Cahaya) Berbasis Web", Fakultas Teknik Industri Institut Teknologi Nasional, 2016, hal.1.

[3] Purnomo, Rezak A., Dahnial Syauqy, Mochammad Hannats Hanafi, "Implementasi Metode Fuzzy Sugeno Pada Embedded System Untuk Mendeteksi Kondisi Kebakaran Dalam Ruangan", Jurnal Pengembangan Teknologi Informasi dan Ilmu Komputer, 2018, vol.2, no.4, hal.1.

[4] Al Faritsy, Ari Zaqi., Yohannes Anton Nugroho, "Pengukuran Lingkungan Kerja Fisik dan Operator untuk Menentukan Waktu Istirahat Kerja", Jurnal Ilmiah Teknik Industri, vol.16 (2), hal.109, 2017.

[5] Christian, Joko., Nurul Komar, "Prototipe Sistem Pendeteksi Kebocoran Gas LPG menggunakan Sensor Gas MQ2, Board Arduino Duemilanove, Buzzer, dan
Arduino GSM Shield pada PT. Alfa Retailindo (Carrefour Pasar Minggu)", Jurnal TICOM, vol.2, no.1, 2013, hal.58.

[6] N.H, Syarifah Apriyanti., Yulisa Fitrianingsih, dan Suci Pramadita, "Analisis Konsentrasi Karbon Monoksida (CO) pada Ruang Parkir Ayani Mega Mall Kota Pontianak", Program Studi Teknik Lingkungan, Jurusan Teknik Sipil, Fakultas Teknik Universitas Tanjungpura, hal.2. 